\title{
History of Canadian Anaesthesia
}

\section{William Marsden $(1807-1885)$}

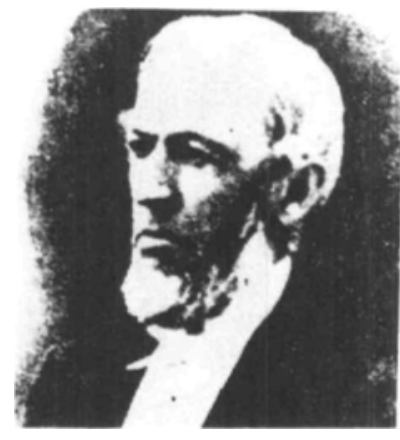

In the days before Canada was born out of Upper Canada and Lower Canada, successful physicians had to be versatile as well as competent. Some of them were so versatile that they would have succeeded in any branch of medicine, and even in any other profession had their choice of career been different; and so it is not surprising that these generalists were remarkably proficient in administering anaesthesia in the earliest days of this new field of medicine. Everyone was a pioneer, and the solving of problems became part of the daily round. Thus E.D. Worthington, of Sherbrooke (portrayed earlier by Holland (Can J Anaesth 1990; 37: 250)), solved the problem of lack of a manufactured ether inhaler in 1847 by making his. own, using such primitive but available items as an ox bladder and an umbrella handle. Medical centres like Boston, London, Edinburgh and Paris, were far away, and it was necessary to fall back on one's own intellectual and technical versatility in order to administer anaesthesia safely and efficiently in the 1840s. Representative of this breed of physician was another Québec physician, William Marsden, who, like Worthington, was one of the first physicians in Canada to administer chloroform.

Marsden, who was born in Lancashire, England in 1807. came to Québec in 1812. He practised in the city of Québec for more than half a century, and in doing so rose to the very top of his profession. He shone in everything he did. Medical students at Laval knew him for his teaching, which embraced subjects as diverse as botany, anatomy and physiology, materia medica and surgery. Physicians in those epidemically troubled times knew him for his literary ability, which enabled him to write an "Essay on the Contagion, Infection, Portability, and Communicability of the Asiatic Cholera, in Its Relations to Quarantine, with a History of Its Origin and Course in Canada from 1832." (Versatility obviously included a talent for circumlocution also.) Marsden was known in organized medicine, too: in addition to being for many years President and Senior Governor of the College of Physicians and Surgeons of Québec, he was in the memorable year of 1867 President of the Québec Medical Society
- and the moving spirit behind the founding that year of the Canadian Medical Association. He also found time to be a member of the Medical Society of London and of the Medical Botanical Society of London. And after the introduction of chloroform, his versatility enabled Marsden to make an early and useful contribution to the understanding of this anaesthetic.

Like many of his colleagues, Marsden was immediately interested in anaesthesia. Though not the first to administer chloroform in Lower or Upper Canada - Worthington, of Sherbrooke, did so on January 24, 1848 - Marsden was the first to describe the effects of chloroform so clearly. This he did as early as February 15, 1848, following the administration of chloroform to two patients on February 4, 1848.

Marsden's experience led him to conclude that "the result ... fully establishes the utility of this invaluable discovery." At so early a stage in the evolution of anaesthesia, confirmation of the efficacy of chloroform was necessary, and Marsden, who was a much respected figure in medicine, provided this confirmation.

In writing about Marsden, A.D. Kelly, once Secretary of the Canadian Medical Association, quoted the concluding lines of a prayer written by Sir Francis Drake: "O Lord God, when thou givest to thy servants to endeavour any great matter grant us also to know that it is not the beginning but the continuing of the same until it be thoroughly finished which yieldeth the true glory." While much is made of priority in history, in anaesthesia, as in other fields of human endeavour, glory indeed comes from the "continuing" of what has to be done in establishing validity and value. And so to William Marsden, glory may be justly given, for in continuing to study anaesthesia once it had been introduced he helped to lay the basis for the medicine that we practise - the "great matter" that we so often take for granted, forgetting the work that has been done by pioneers in earlier times.

David A.E. Shephard 